\title{
Experiencia con símbolos y comprensión de dibujos en niños pequeños de distintos contextos socioeconómicos*
}

\author{
Symbolic Experience and Young Children's Comprehension of Drawings \\ in Different Socioeconomic Contexts \\ Experiência com símbolos e compreensão de desenhos em crianças pequenas \\ de diferentes contextos socioeconómicos
}

\author{
Analía M. Salsa ${ }^{* *}$, María Belén Gariboldi** \\ Consejo Nacional de Investigaciones Cientificas y Técnicas (CONICET)
}

Doi: http://dx.doi.org/10.12804/revistas.urosario.edu.co/apl/a.4332

\section{Resumen}

El propósito de esta investigación fue explorar las relaciones entre la comprensión temprana de dibujos por parte de niños de nivel socioeconómico medio (NSE medio) y bajo (NSE bajo) y las experiencias con símbolos en el contexto familiar. Para ello, 28 niños de entre $30 \mathrm{y}$ 38 meses resolvieron una tarea de correspondencias en la que debían establecer relaciones entre cinco objetos y sus dibujos en lápiz negro. Sus madres contestaron un cuestionario sobre la cantidad y la variedad de imágenes en los hogares y las actividades compartidas por adultos y niños con estas representaciones. Los resultados muestran que solamente los niños de NSE medio demostraron comprender la relación dibujo-referente; el desempeño simbólico se asoció principalmente con la presencia en los hogares de recursos con imágenes para niños (DVD y libros infantiles) y con las interacciones adulto-niño con estos recursos, como las experiencias conjuntas con imágenes audiovisuales, la lectura de cuentos y la asistencia materna al dibujar.

Palabras clave: dibujos, comprensión, experiencia simbólica, nivel socioeconómico.

\section{Abstract}

The purpose of this research was to explore the relationships between children's early comprehension of drawings in two socioeconomic groups (middle- and low-SES) and the experiences with symbols at home. Twenty-eight children between 30 and 38 months of age solved a matching task in which they had to relate five objects with their black-and-white line drawings; their mothers completed a questionnaire regarding the quantity and variety of pictures at home and the shared activities between adults and children with these

* $\quad$ Este trabajo ha sido realizado gracias a la financiación otorgada por el CONICET en el marco del proyecto PIP 2012-2014 N. 0864 (bajo la dirección de la primera autora). Las autoras agradecen a los niños y docentes que participaron en la investigación.

** Instituto Rosario de Investigaciones en Ciencias de la Educación (IRICE) - CONICET. Correspondencia: Bv. 27 de febrero 210 bis, IRICE (CONICET), Rosario, Argentina. Correo electrónico: salsa@irice-conicet.gov.ar

*** Instituto Rosario de Investigaciones en Ciencias de la Educación (IRICE) - CONICET.

Cómo citar este artículo: Salsa, A. M., \& Gariboldi, M. B. (2018). Experiencia con símbolos y comprensión de dibujos en niños pequeños de distintos contextos socioeconómicos. Avances en Psicología Latinoamericana, 36(1), 29-43. doi: http:// dx.doi.org/10.12804/revistas.urosario.edu.co/apl/a.4332 
symbols. The results show that only middle-SES children were able to understand the drawing-referent relation; symbolic performance was mainly associated with the presence of resources with children's images at home (DVD and children's books) and with adultchild interactions with these resources, such as joint experiences with audio-visual images, storytelling and maternal assistance when children draw.

Keywords: Drawings, comprehension, symbolic experience, socioeconomic level.

\section{Resumo}

O propósito desta pesquisa foi explorar as relações entre a compreensão temporã de desenhos em crianças de nível socioeconómico meio (NSE médio) e baixo (NSE baixo) e as experiências 30 e 38 meses resolveram uma tarefa de correspondências na que deviam estabelecer relações entre cinco objetos e seus desenhos em lápis preto; suas mães contestaram um questionário sobre a quantidade e a variedade de imagens nos lares e as atividades partilhadas por adultos e crianças cm estas representações. Os resultados mostram que só as crianças de NSE médio demostraram compreender a relação desenho-referente; o desempenho simbólico associou-se principalmente com a presença nos lares de recursos com imagens para crianças (DVD e livros infantis) e com as interações adulto-criança com estes recursos, como as experiências conjuntas com imagens audiovisuais, a leitura de livros e a assistência materna ao desenhar.

Palavras-chave: desenhos, compreensão, experiência simbólica, nível socioeconómico.

En las culturas occidentales, fotografías, dibujos, mapas, numerales, escritura, son solo algunos ejemplos de la variedad inmensa de representaciones externas que forman parte de la vida cotidiana. Aún antes de aprender a interpretar, producir o usar estas representaciones, los niños participan en diferentes actividades con ellas: observan a sus padres escribir notas y listas de compras y a sus hermanos dibujar; 'leen' libros de imágenes, miran fotos familiares e imágenes de televisión, en DVD y dispositivos digitales (smartphones, tablets). El presente estudio se centra precisamente en las relaciones entre la experiencia con símbolos ${ }^{1}$ y la comprensión de representaciones basadas en la imagen por parte de niños de distintos contextos socioeconómicos.

Las representaciones basadas en la imagen o figurativas, las fotografías, las imágenes audiovisuales y algunos tipos de dibujos se caracterizan por la similitud perceptual con el referente que representan: algunas propiedades de la representación (forma, tamaño, posición espacial) remiten directamente a las mismas propiedades del referente (Martí, 2003, 2012). Por ejemplo, en un dibujo de un perro y en un perro real, cabeza y tronco están conectados, las orejas están a ambos lados de la cabeza y las partes del cuerpo poseen una forma similar y un tamaño proporcional. La denominación de 'icónico' (Peirce, 1932) ha sido también propuesta para dar cuenta de estas representaciones vinculadas con sus referentes por una similitud morfológica. Sin embargo, las representaciones figurativas no tienen un significado directo y transparente para los niños pequeños; la comprensión y el uso de imágenes como símbolos es un proceso de desarrollo largo y complejo, de especial importancia, ya que concede a las personas un instrumento de gran valor cognitivo y cultural.

En el transcurso del tercer año de vida, entre los 30 y 36 meses, los niños demuestran comprender y usar fotografías y dibujos en distintos tipos de tareas, en las que deben establecer correspondencias entre las representaciones y sus referentes (Callaghan, 1999, 2000; Harris, Kavanaugh \&

1 En este artículo definimos 'símbolo' siguiendo la propuesta de DeLoache (1995), como "algo que alguien propone con la intención de representar una entidad diferente de la utilizada para representar" (p. 109). Esta perspectiva considera a los símbolos como 'representaciones externas' (Goldin, 1998), en oposición a las representaciones internas o mentales. 
Dowson, 1997; Vivaldi \& Salsa, 2014) o utilizar las imágenes como fuente de información para buscar objetos escondidos (DeLoache, 1987, 1991; DeLoache \& Burns, 1994). Antes de esa edad, los bebés exploran las imágenes y juegan con ellas como si fueran otros objetos cualesquiera, frotándolas, mordiéndolas o intentando tomar los objetos representados (DeLoache, Pierroutsakos, Uttal, Rosengren, \& Gottlieb, 1998; Pierroutsakos \& DeLoache, 2003). DeLoache (2002) señala que al menos dos factores podrían explicar este cambio en la conducta infantil. El primero se refiere a la naturaleza dual de las representaciones figurativas al ser, a la vez, objetos físicos interesantes en sí mismos y representaciones que denotan otra cosa. A los niños menores de 30 meses les resulta difícil comprender la función simbólica de una imagen porque su atención estaría capturada por las propiedades físicas del objeto (su color, brillo, textura).

El segundo factor está relacionado con la experiencia simbólica, estos son los efectos acumulativos de la exposición a distintas clases de representaciones externas y a distintos ejemplares de un mismo tipo de representación. Según DeLoache (2002), a medida que los niños crecen incrementan sus experiencias con representaciones externas y desarrollan una capacidad general o 'sensibilidad simbólica' para buscar y reconocer relaciones símbolo-referente (ver también Troseth, Casey, Lawver, Walker \& Cole, 2007). Desde esta perspectiva, la experiencia simbólica parecería quedar reducida a los efectos de la edad.

Siguiendo a Vygotsky (1978), autoras como Liben (1999, 2008) y Callaghan (2013) ofrecen una mirada diferente. Además del contacto con los símbolos en el entorno inmediato, el apoyo social y las experiencias infantiles dibujando o aprendiendo técnicas gráficas serían componentes centrales de la experiencia simbólica. Así como sucede en la adquisición del lenguaje oral, el desarrollo del conocimiento sobre las imágenes dependería del apoyo en forma de andamiaje que los adultos ofrecen al usar estas representaciones en las interacciones con bebés y niños pequeños. También, Tomasello $(1999,2014)$ sostiene que las formas de aprendizaje cultural son cruciales, ya que las imágenes adquieren su significado en una matriz social; son artefactos creados por el hombre para servir a una función simbólica y comunicativa. Para aprender a usar imágenes, los niños necesitan comprender que estos símbolos están motivados por una intención comunicativa que tiene lugar en el contexto de una escena atencional conjunta que le provee su fundamento socio-cognitivo. En este contexto, los niños comienzan a entender cuál es el significado de la representación y con qué función específica la utiliza su compañero comunicativo.

En las últimas dos décadas, diversas investigaciones han aportado evidencia sobre cómo los niños aprenden a comprender y producir imágenes en interacción con usuarios más competentes. Los adultos proveen a los niños asistencia verbal y no verbal en actividades conjuntas con dibujos: las madres ofrecen demostraciones gráficas e instrucciones explícitas acerca de cómo crear las imágenes cuando dibujan con sus hijos pequeños (Braswell, 2001; Braswell \& Callanan, 2003; Yamagata, 1997). Estudios de intervención han demostrado además que la exposición repetida a un adulto que dibuja y usa sus dibujos como símbolos facilita la emergencia de la comprensión de la relación dibujo-referente antes de los 30 meses (Callaghan \& Rankin, 2002).

Es importante señalar que esta dimensión social de la experiencia con símbolos no se limita a las interacciones cara a cara. Un apoyo empírico fuerte a esta idea proviene de un estudio reciente llevado a cabo por Callaghan et al. (2011) en tres contextos culturales diferentes, comunidades rurales en Canadá, Perú e India. En una tarea de comprensión de dibujos, los niños canadienses se desempeñaron exitosamente a los 30 meses, más de un año y medio antes que los otros dos grupos de niños. En una tarea de producción gráfica, los niños canadienses demostraron ser capaces de crear 
dibujos figurativos alrededor de los 48 meses, entre un año y un año y medio antes que sus pares de Perú e India. Una serie de entrevistas a las madres reveló que únicamente los niños en Canadá tenían experiencias variadas con imágenes audiovisuales e impresas en libros infantiles y fotos familiares. El contacto con imágenes en las otras comunidades se limitaba a unas pocas ilustraciones religiosas presentes en los hogares.

El estudio que aquí se presenta explora las relaciones entre la experiencia con símbolos y la comprensión de dibujos desde una perspectiva diferente. Si la adquisición del conocimiento sobre las imágenes depende del apoyo social de usuarios más competentes, habría razones para pensar que el nivel socioeconómico, en un mismo grupo cultural, podría implicar diferencias en las experiencias con símbolos y en la emergencia de este conocimiento. Numerosas investigaciones muestran que la frecuencia y la complejidad de las actividades lingüísticas que comparten padres y niños pequeños difieren ampliamente en función del nivel socioeconómico de las familias, variaciones que parecen impactar en el desarrollo del lenguaje oral (Hoff-Ginsberg, 1991; Hoff, 2003; Ninio, 1980; Peralta \& Salsa, 2001). Resultados similares fueron encontrados en las experiencias entre padres y niños menores de 48 meses con representaciones externas como la escritura (Levin \& Aram, 2005; Treiman et al., 2015) y el número (Anders et al., 2012; Gunderson \& Levine, 2011).

Hasta donde se pudo conocer en este estudio, son escasas las investigaciones que se focalizaron en el nivel socioeconómico y la comprensión temprana de representaciones figurativas. En un estudio realizado por Salsa (2012), se observó que niños de nivel socioeconómico medio (NSE medio) eran capaces de usar fotografías y dibujos como símbolos a los 30 meses, en línea con lo informado en trabajos previos (Callaghan, 2000; DeLoache, 1991; DeLoache \& Burns, 1994); por su parte, niños de nivel socioeconómico bajo (NSE bajo) demostraron comprender y usar estas imágenes más tardíamente, las fotografías alrededor de los 36 meses y los dibujos a los 42 meses.

La presente investigación se propone explorar las relaciones entre la comprensión de dibujos en niños pequeños de NSE medio y bajo y las experiencias con símbolos en el contexto familiar. Para alcanzar este objetivo, en primer lugar, se comparó el desempeño de niños de entre 30 y 38 meses en una tarea de correspondencias dibujo-referente, prueba diseñada por Callaghan $(1999,2000)$ y adaptada por Salsa (2012). En esta tarea, los niños deben relacionar cinco dibujos en lápiz negro con sus referentes, objetos simples que presentan diferencias entre sí (combinaciones de forma o tamaño), pero que se pueden identificar con un mismo nombre ('pelota'). De esta manera, es posible controlar el papel de las etiquetas verbales en la comprensión de las imágenes: los niños tienen que usar el dibujo como símbolo de un referente específico y el nombre del objeto cuando observan la imagen no puede ayudarlos a establecer la relación dibujo-referente.

En segundo lugar, se administró a las madres un cuestionario a fin de describir las experiencias en el contexto familiar con distintos tipos de representaciones, imágenes audiovisuales, fotografías, ilustraciones y dibujo. El cuestionario permitió recabar información sobre: (i) la cantidad y la variedad de imágenes en los hogares de NSE medio y bajo; y (ii) las actividades compartidas por adultos y niños con estas representaciones. La necesidad de indagar ambas dimensiones se fundamenta en los distintos enfoques sobre la experiencia simbólica que se revisaron hasta aquí: (i) la propuesta de DeLoache (2002), centrada principalmente en el contacto del niño con diferentes representaciones externas; y (ii) un enfoque anclado en la perspectiva sociocultural (Callaghan, 2013; Tomasello, 1999) que destaca el rol de las interacciones comunicativo-educativas entre adultos y niños con imágenes. 


\section{Método}

\section{Participantes}

En este estudio participaron 28 díadas de madres y sus niños (rango de edad: 30-38 meses), 14 de cada nivel socioeconómico. Los niños de NSE medio $\left(M_{\text {edad }}=34,6\right.$ meses, 7 niñas $)$ concurrían a dos jardines de infantes de gestión privada de la zona céntrica de la ciudad de Rosario (provincia de Santa Fe, Argentina); los niños de NSE bajo $\left(M_{\text {edad }}=33,9\right.$ meses, 8 niñas) a dos jardines públicos dependientes de la Municipalidad de Rosario, ubicados en la periferia de la ciudad y destinados a sectores con necesidades básicas insatisfechas. Las cuatro instituciones trabajaban siguiendo lineamientos curriculares básicos comunes (Proyecto Pedagógico Provincial para el Nivel Inicial), en los que las representaciones figurativas no eran objeto explícito de enseñanza. La media de edad de las madres era de 33,2 años en el NSE medio y de 26,6 años en el NSE bajo.

Además de la asistencia a los jardines de infantes, al asignar a las díadas a los grupos NSE medio y NSE bajo se consideró el nivel educativo y la ocupación de las madres (Hoff, Laursen \& Tardif, 2002). Con respecto a los niveles de escolaridad, en el NSE medio el $7 \%$ de las madres había completado 12 años de escolaridad como mínimo (curso completo de los niveles primario y medio en Argentina); el $93 \%$ poseía más de 15 años de escolaridad (nivel superior técnico o universitario). En el NSE bajo el 29\% de las madres tenía solamente 7 años de escolaridad (nivel primario) y el $71 \%$ restante entre 7 y 10 años (nivel primario y curso incompleto del nivel medio). La mayoría de las madres de NSE medio trabajaban en sus profesiones (58\%) o en el comercio (21\%); el 71,5\% de las madres de NSE bajo se desempeñaban como empleadas domésticas. En el $86 \%$ de las familias de NSE bajo el ingreso económico principal era algún tipo de asistencia gubernamental.

\section{Materiales y procedimiento}

Los niños resolvieron una tarea de correspondencias en la que debían establecer relaciones entre una serie de dibujos figurativos y sus objetos referentes y a las madres se les administró un cuestionario. En ambos casos se trabajó en una sala disponible del jardín de infantes al que concurría el niño. Respecto a los resguardos éticos, se informó a las madres los detalles y requerimientos del estudio y se les solicitó en forma escrita autorizar su participación y la de sus hijos, asegurándoles confidencialidad de la información.

Para la tarea de correspondencias se utilizó un conjunto de cinco objetos de color naranja construidos con esferas de poliestireno expandido y palillos de madera: (i) una pelota; (ii) una pelota más pequeña que 1 con palillos clavados por toda su superficie; (iii) una pelota más pequeña que 1 y 2; (iv) dos pelotas unidas; y (v) una varilla de madera. Para que la tarea fuera atractiva para los niños, se empleó un túnel de colores construido con un caño plástico $(15 \mathrm{~cm}$ x $90 \mathrm{~cm})$ y cinco cajas de color rojo (20 cm x $14 \mathrm{~cm}$ ), cada una con un dibujo en lápiz negro de uno de los objetos en su interior (figura 1).

La sesión experimental con el niño duraba aproximadamente 20 minutos y comenzaba con algunos minutos de juego libre para que el niño interactuara con la experimentadora. Luego, la experimentadora lo invitaba a jugar un juego con dibujos, presentaba el túnel y explicaba: "Vamos a jugar con algunos juguetes, dibujos de los juguetes y este túnel". En primer término, la experimentadora mostraba uno a uno los objetos, identificándolos a todos como 'juguetes'. Después la experimentadora decía: "Yo voy a arrojar los juguetes por el túnel y tú vas a tener que guardar cada uno en una caja”. Para presentar las cajas la experimentadora explicaba: "Cada juguete tiene su caja. Tú vas a saber cuál es la caja de cada uno porque las cajas tienen un dibujo de su juguete". A continuación, mostraba una a una las cajas diciendo "Esta es la caja de este 


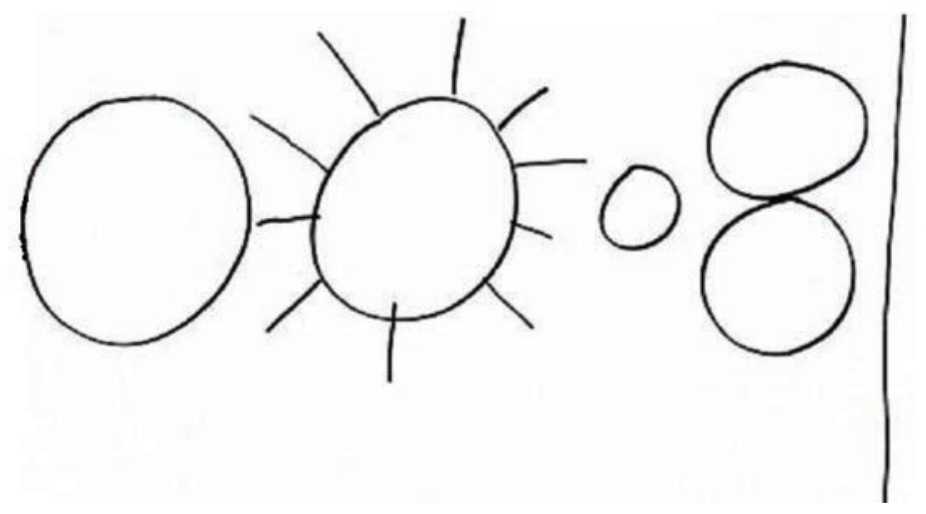

Figura 1. Dibujos de los objetos empleados en la tarea de correspondencias

juguete" (señalando el dibujo) y alineaba las cajas frente al túnel. En ningún momento el niño observaba los dibujos y sus referentes simultáneamente.

Al finalizar la presentación de los materiales, se repetía la consigna: "Yo voy a arrojar los juguetes por el túnel y tú vas a tener que guardar cada uno en su caja”. Cada vez que arrojaba un objeto por el túnel la experimentadora decía: “ ¡A buscar la caja de este juguete!”. El orden en que los objetos eran arrojados por el túnel fue contrabalanceado aleatoriamente de manera que la mitad de los niños de cada grupo realizara la tarea en un orden y la otra mitad en el orden inverso. Si la elección objeto-dibujo era incorrecta no se corregía al niño y se esperaba algunos segundos antes de retirar el objeto de la caja para observar si modificaba espontáneamente su elección. En cada uno de los cinco ensayos de la tarea, la experimentadora retiraba el objeto de la caja para que el niño tuviera que elegir el dibujo correcto entre los cinco dibujos del set. Una segunda experimentadora observaba la sesión y tomaba nota del comportamiento del niño en un protocolo diseñado para tal fin; registraba si las elecciones del niño eran correctas o incorrectas, si eran incorrectas qué dibujo seleccionaba y si corregía espontáneamente su elección y la conducta verbal y no verbal del niño.

Se administró el cuestionario a las madres en forma individual antes o después de la sesión con su hijo: solamente en los casos que se hacía antes, se invitaba a las madres a observar la tarea de correspondencias. La administración del cuestionario duraba 30 minutos aproximadamente. El cuestionario comenzaba con una serie de preguntas acerca de la composición familiar, el nivel de escolaridad y la ocupación de la madre, entre otros aspectos socio-demográficos. Las preguntas sobre las experiencias con imágenes se organizaban en tres bloques: (i) imágenes audiovisuales (televisión, DVD y video); (ii) fotografías e ilustraciones; y (iii) experiencias gráficas. En total se realizaron 33 preguntas, de las cuales 20 eran de alternativas de selección múltiple (de tres a cinco opciones de respuesta) y 13 de selección dicotómica (sí o no).

Se construyó el cuestionario tomando ítems sobre la cantidad y la variedad de imágenes de un instrumento utilizado en Troseth et al. (2007) e incluyendo ítems sobre actividades conjuntas en el hogar surgidos de los datos obtenidos en entrevistas a madres que participaron en estudios previos llevados a cabo por el equipo de investigación. Se aplicó una primera versión del cuestionario a una muestra piloto de 10 madres distribuidas homogéneamente en los jardines de infantes que participaron del estudio y luego se realizaron algunas modificaciones (en la formulación de las preguntas y opciones de respuesta que presentaron dificultades de interpretación), lo que dio lugar al cuestionario definitivo. 
En cada uno de los tres bloques, primero se indagaba sobre la presencia en el hogar de distintos tipos de imágenes y luego sobre las actividades entre adultos y niños con estas representaciones. Por ejemplo, en el bloque imágenes audiovisuales, la pregunta "Si en su casa cuentan con reproductor de DVD, ¿cuántos DVD infantiles poseen?” tenía como opciones de respuesta cuatro rangos, desde "Ninguno" hasta "Más de 20". La pregunta "Cuando su hijo/a mira TV, DVD o videos en algún dispositivo digital, ¿acostumbra hacerlo acompañado por algún adulto?" incluía tres opciones, "Nunca", "A veces" y "Siempre"; "Si su respuesta es 'Siempre' o 'A veces', ¿suelen conversar acerca de lo que miran juntos?" se respondía dicotómicamente ("Sí" o "No"). En el bloque fotografías e ilustraciones, la pregunta "Si en su hogar hay libros infantiles, ¿cuántos libros, aproximadamente, tienen?” tenía cuatro opciones de respuesta, desde "Menos de 5 " hasta "Más de 20", mientras que la pregunta “¿Alguien en su casa le lee al niño?” solamente dos ("Sín"y "No").

\section{Resultados}

De acuerdo con el objetivo del estudio, el análisis de los datos estuvo orientado primero a la comparación del desempeño de los niños en la tarea de correspondencias en función de su nivel socioeconómico. En segundo lugar, se analizaron las respuestas maternas al cuestionario con el fin de describir las experiencias con distintos tipos de imágenes también en función del nivel socioeconómico. Finalmente, se examinaron las relaciones entre el desempeño infantil y las experiencias con imágenes que arrojaron diferencias entre el NSE medio y bajo. En todos los casos, se emplearon pruebas estadísticas no paramétricas debido a la distribución asimétrica de la muestra y a su tamaño pequeño para asumir normalidad.

\section{Comprensión de dibujos y nivel socioeconómico}

El análisis del desempeño infantil en la tarea de correspondencias se realizó sobre el número de ensayos correctos (se utilizan porcentajes en el texto para facilitar la interpretación de los datos). Para codificar a un ensayo como correcto, el niño debía guardar en su primer intento el objeto en la caja que contenía su dibujo (máximo $=5$ ). Cabe destacar que no se encontraron diferencias de ejecución por sexo ni por orden de presentación de los objetos en ninguno de los dos grupos de niños.

Los resultados muestran que el desempeño fue diferente en función del nivel socioeconómico: los porcentajes de ensayos correctos fueron $97 \%$ en el grupo de NSE medio y $34 \%$ en el grupo de NSE bajo. Únicamente la ejecución de los niños de NSE medio fue significativamente superior a la esperada por azar $(0,20$ con base a cinco lugares posibles para guardar un objeto $)\left(\chi^{2}=31, p=0,001\right)$. El análisis estadístico confirmó diferencias significativas entre el rendimiento de ambos grupos (prueba de Mann Whitney: $U=16, p=.001, d=0,837$ ).

Como muestra la figura 2 , estos resultados se observan más claramente al analizar el rendimiento individual. Se consideró que un niño resolvía la tarea en forma correcta si emparejaba el objeto con su dibujo al menos en cuatro de los cinco ensayos $(80 \%)$. Mientras que los 14 niños de NSE medio cumplieron con este criterio de éxito en la tarea, solamente 2 niños lo hicieron en el grupo de NSE bajo: los 12 niños restantes resolvieron correctamente entre tres y ningún ensayo. Cuando la primera elección fue incorrecta, no se registraron correcciones espontáneas en ninguno de los grupos.

\section{Experiencias con imágenes y nivel socioeconómico}

Se presentan los resultados del cuestionario agrupando las respuestas maternas a sus tres 


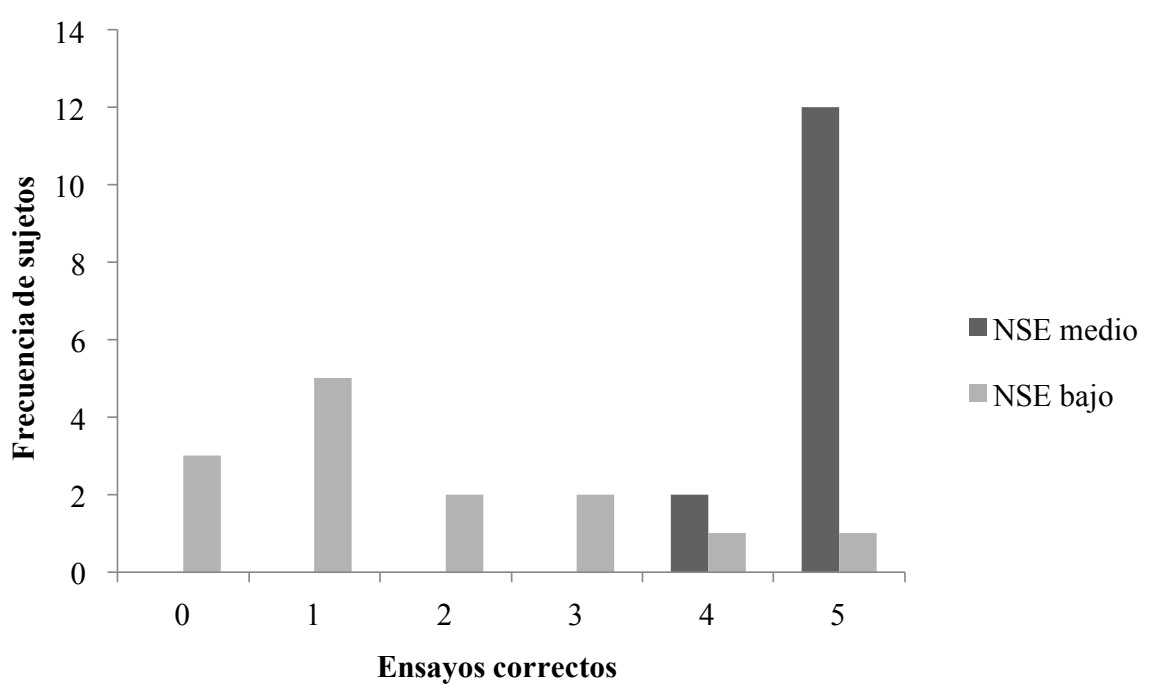

Figura 2. Distribución de frecuencias de sujetos por número de ensayos correctos en función del nivel socioeconómico

bloques en función de: (i) la presencia en el hogar de distintos tipos de imágenes y (ii) las actividades compartidas entre adultos y niños con estas representaciones. Para estimar la asociación entre las respuestas maternas y el nivel socioeconómico de las díadas, se aplicó un análisis estadístico de comparación de frecuencias (prueba de $J i$ cuadrado).

\section{Presencia de imágenes}

En relación con las imágenes audiovisuales, como puede observarse en la tabla 1, la presencia de televisores era similar en los hogares de ambos niveles socioeconómicos, no así de computadoras y de dispositivos para filmación (videocámaras y/o smartphones) con un predominio mayor en el NSE medio: estas frecuencias fueron significativamente diferentes $\left(\chi^{2}(1)=7,04, p=0,008\right.$ y $\chi^{2}(1)$ $=13,26, p=0,001$, respectivamente). Aunque en los dos niveles socioeconómicos la presencia de reproductores de DVD era similar, las madres de NSE medio y bajo informaron poseer distinta cantidad de DVD infantiles en sus hogares. Mientras que en el $93 \%$ de las familias de NSE medio había más de 10 DVD infantiles (opciones de respuesta “Entre 10 y 20" y "Más de 20"), en el NSE bajo el $64 \%$ de las madres contestó tener no más de 5 DVD infantiles y el $22 \%$ ninguno $\left(\chi^{2}(3)=18,6, p\right.$ $=0,001)$. La presencia de consolas de videojuegos fue baja tanto en el NSE medio como en el NSE bajo.

Con respecto a los materiales impresos con imágenes, un número similar de familias en ambos niveles socioeconómicos contaban con periódicos y revistas para adultos, siendo mayor la presencia de libros para adultos en el NSE medio que en el NSE bajo $\left(\chi^{2}(1)=5,6, p=0,01\right)$. En general, en los hogares de los dos niveles socioeconómicos había el mismo tipo de materiales con ilustraciones para niños: revistas, libros de cuentos, libros para colorear y libros de texto escolares. Sin embargo, el número de familias que contaban con libros de cuento y para colorear fue significativamente mayor en el NSE medio que en el NSE bajo $\left(\chi^{2}(1)=7,63, p\right.$ $=0,006$ y $\chi^{2}(1)=4,09, p=0,04$, respectivamente).

En efecto, sobre la cantidad de libros de cuentos en el hogar, el $36 \%$ de las madres de NSE medio informó tener entre 5 y 10 libros infantiles, el $28 \%$ entre 10 y 20 y el $36 \%$ más de 20 libros. Por el contrario, el $43 \%$ de las madres de NSE bajo contestó no tener libros de cuento en sus hogares, el $28,5 \%$ menos de 5 y solo el $28,5 \%$ restante entre 5 y 10 libros. Estas frecuencias fueron significativamente 
diferentes $\left(\chi^{2}(4)=19,1, p=0,001\right)$. Finalmente, en los dos niveles socioeconómicos había fotografías de los niños y su familia en todos los hogares.

Tabla 1

Número de familias con imágenes audiovisuales e impresas en sus hogares en función del nivel socioeconómico

$\begin{array}{cc}\text { Nivel socioeconómico } \\ \text { NSE medio } \\ (n=14)\end{array} \quad \begin{gathered}\text { NSE bajo } \\ (n=14)\end{gathered} \quad p=$

Imágenes audiovisuales

\begin{tabular}{lrrr} 
Televisión & 14 & 14 & - \\
DVD & 14 & 12 & $\mathrm{~ns}$ \\
Computadora & 11 & 4 & 0,008 \\
Videocámaras & 9 & 0 & 0,001 \\
Videojuegos & 4 & 4 & $\mathrm{~ns}$ \\
Imágenes impresas & 14 & 14 & - \\
Fotografías & 7 & 10 & $\mathrm{~ns}$ \\
Periódicos & 5 & 5 & $\mathrm{~ns}$ \\
Revistas adultos & 11 & 8 & $\mathrm{~ns}$ \\
Revistas infantiles & 8 & 2 & 0,01 \\
Libros adultos & 14 & 8 & 0,006 \\
Libros de cuento & 12 & 7 & 0,04 \\
Libros para colorear & 9 & 11 & $\mathrm{~ns}$ \\
Libros escolares & & & \\
\hline
\end{tabular}

\section{Actividades conjuntas con imágenes}

Cuando se preguntó si los niños acostumbraban a mirar televisión, DVD y/o video acompañados por algún adulto del contexto familiar, el $57 \%$ de las madres de NSE medio contestó "A veces" y el $43 \%$ "Siempre"; el 36\% de las respuestas de las madres de NSE bajo fueron "Nunca", el 36\% "A veces" y el 28\% "Siempre". Cuando las respuestas fueron "A veces" y "Siempre", las madres de los dos grupos conversaban con sus hijos acerca de lo que miraban juntos. Las diferencias por nivel socioeconómico resultaron significativas $\left(\chi^{2}(2)\right.$
$=6, p=0,048)$, evidenciando que la interacción con imágenes audiovisuales como una experiencia compartida por niños y adultos parecería ser más frecuente en el NSE medio.

Se registró también una diferencia marginalmente significativa en la frecuencia en que madres y niños solían mirar juntos material ilustrado (libros con imágenes o imágenes en revistas), focalizando la interacción en conversar sobre las imágenes (no leer): el $93 \%$ de las madres de NSE medio y el $57 \%$ de las madres de NSE bajo respondieron que era una actividad frecuente en sus hogares (opción de respuesta "Más de una vez a la semana") $\left(\chi^{2}(1)=\right.$ $4,76, p=0,077)$. Más claras fueron las diferencias en relación con la lectura de cuentos. En todas las familias de NSE medio (100\%) un adulto leía o relataba historias al niño a partir de un libro, mientras que esto solo sucedía en el $36 \%$ de las familias de NSE bajo $\left(\chi^{2}(1)=11,2, p=.002\right)$. El $50 \%$ de las madres de NSE medio reportó leer un cuento a sus hijos "Todos los días", el 43 \% "Más de una vez a la semana" y el $7 \%$ restante "Algunas veces por mes"; las frecuencias de respuestas en el NSE bajo fueron $21 \%$ para "Más de una vez a la semana", $14 \%$ para "Algunas veces por mes" y $65 \%$ "Nunca" $\left(\chi^{2}(3)=17 \cdot 3, p=0,001\right)$.

Otra serie de preguntas exploraba las experiencias gráficas. Todos los niños de NSE medio y bajo acostumbraban a dibujar en sus hogares: el $79 \%$ de los niños de NSE medio y el $50 \%$ de los niños de NSE bajo solían compartir esta actividad con sus madres. En estos casos, se indagó acerca de los apoyos que las madres solían brindar (tabla 2). El $43 \%$ de las madres de NSE medio y el $28,5 \%$ de las madres de NSE bajo contestaron realizar demostraciones gráfico-espaciales (ayudar a sostener el lápiz, usar la hoja de papel o dibujar para que los niños copien); el $50 \%$ de las madres de NSE medio y el 28,5\% de las madres de NSE bajo daban instrucciones verbales explícitas (instrucciones sobre cómo dibujar el objeto o la persona que el niño quiere representar, qué formas hacer y en qué orden) y el $64 \%$ de las madres de NSE 
medio y el $21 \%$ de las madres de NSE bajo daban instrucciones implícitas (conversar sobre las características del objeto o la persona que los niños quieren dibujar). Finalmente, todas las madres afirmaron brindar evaluaciones positivas cuando los niños dibujaban (esto es, felicitarlos por su producción gráfica). El único tipo de ayuda que registró diferencias significativas por nivel socioeconómico fue instrucciones implícitas $\left(\chi^{2}(1)\right.$ $5,25, p=0,022)$.

Tabla 2

Apoyos maternos cuando madres y niños dibujan juntos en el hogar

\begin{tabular}{lccr}
\hline & \multicolumn{2}{c}{ Nivel socioeconómico } & \\
\cline { 2 - 3 } & $\begin{array}{c}\text { NSE medio } \\
(n=11)\end{array}$ & $\begin{array}{c}\text { NSE bajo } \\
(n=7)\end{array}$ & $p=$ \\
\hline $\begin{array}{l}\text { Demostraciones gráfi- } \\
\text { co-espaciales }\end{array}$ & 6 & 4 & $\mathrm{~ns}$ \\
Instrucciones explícitas & 7 & 4 & $\mathrm{~ns}$ \\
Instrucciones implícitas & 9 & 3 & 0,022 \\
Evaluaciones positivas & 11 & 7 & $\mathrm{~ns}$ \\
\hline
\end{tabular}

Nota: Las respuestas a esta pregunta del cuestionario no eran mutuamente excluyentes.

Finalmente, resultó beneficioso indagar si los niños demostraban interés por otras formas de representación externa, como la escritura y los numerales (“ ¿Su hijo/a demuestra interés por el lenguaje escrito? Por ejemplo, diferencia letras de dibujos o conoce alguna/s letra/s de su nombre"; “¿Reconoce algún número escrito?”). Mientras que el $71 \%$ de las respuestas de las madres de NSE medio fueron afirmativas para escritura y el $64 \%$ para numerales, solamente el $28 \%$ de las respuestas maternas en el NSE bajo fueron afirmativas para escritura y el $14 \%$ para numerales $\left(\chi^{2}(1)=5,14, p=0,023\right.$ y $\chi^{2}(1)=7,34, p=0,007$, respectivamente).
Tabla 3

Asociación entre el desempeño infantil (presimbólico y simbólico) y las experiencias con imágenes

\begin{tabular}{lrr}
\hline & \multicolumn{1}{c}{$\chi^{2}$} & $p=$ \\
\hline Presencia de imágenes & & \\
Computadora & 6,89 & 0,009 \\
Videocámaras & 9,94 & 0,003 \\
DVD infantiles (cantidad) & 17,63 & 0,001 \\
Libros adultos & 3,31 & $\mathrm{~ns}$ \\
Libros de cuento & 10,18 & 0,002 \\
Libros de cuento (cantidad) & 16,77 & 0,002 \\
Libros para colorear & 6,60 & 0,017 \\
Actividades compartidas & & \\
Mirar juntos imágenes audiovisuales & 8,77 & 0,012 \\
'Lectura' de material ilustrado & 3,11 & $\mathrm{~ns}$ \\
Lectura de cuentos & 9,11 & 0,004 \\
Lectura de cuentos (frecuencia) & 18,92 & 0,000 \\
Instrucciones implícitas al dibujar & 10,22 & 0,001 \\
Otras representaciones & 2,33 & $\mathrm{~ns}$ \\
Interés por la escritura & 8,43 & 0,006 \\
Interés por los numerales & & \\
\hline
\end{tabular}

\section{Comprensión de dibujos y experiencia con imágenes}

En último lugar, se examinó la asociación entre el desempeño infantil en la tarea de correspondencias y el tipo de imágenes y actividades entre niños y adultos que arrojaron diferencias por nivel socioeconómico en el análisis de las respuestas maternas al cuestionario. Para ello, a partir del criterio establecido de éxito en la tarea (al menos cuatro de cinco ensayos correctos $-80 \%$ ) se asignaron los niños a dos grupos: (i) desempeño presimbólico, compuesto por 12 niños de NSE bajo que no alcanzaron el criterio de éxito en la tarea; y (ii) desempeño simbólico, compuesto por los 14 niños de NSE medio y 2 niños de NSE bajo. 
Los resultados de la prueba $J i$ cuadrado (tabla 3 ) indicaron una asociación significativa entre el desempeño de los niños y las distintas dimensiones de la experiencia con imágenes, con excepción de la presencia en los hogares de libros para adultos, la 'lectura' de material ilustrado y el interés de los niños por la escritura. Cabe destacar que la 'lectura' de material ilustrado había arrojado solamente una tendencia a la significación en los análisis informados en el apartado anterior.

Para finalizar, al revisar en detalle las entrevistas a las madres de las dos niñas de NSE bajo con desempeño simbólico en la tarea de correspondencias se observó que sus respuestas presentaban similitudes con las experiencias con imágenes reportadas por las madres de NSE medio. Específicamente, se asemejaban en la variedad de materiales impresos para niños (contando en sus hogares con libros de cuento y para colorear), en la frecuencia de lectura de cuentos ("Más de una vez por semana") y en el tipo de ayudas maternas al dibujar (instrucciones implícitas).

\section{Discusión general}

Sin dejar de considerar la naturaleza exploratoria de este estudio (debido al número reducido de parejas de madres y niños que participaron), los resultados muestran, por un lado, diferencias evolutivas en la comprensión de dibujos figurativos en niños pequeños que crecen y se desarrollan en contextos socioeconómicos diferentes (NSE medio y bajo); por otro lado, que el desempeño simbólico se relaciona principalmente con una presencia mayor en los hogares de NSE medio de recursos con imágenes para niños (DVD y libros infantiles) y con las actividades entre adultos y niños con estas representaciones, como las experiencias conjuntas con imágenes audiovisuales, la lectura de cuentos y el tipo de asistencia materna al dibujar.

En cuanto a la comprensión de dibujos, en línea con investigaciones previas (Callaghan, 1999, 2000; Callaghan \& Rankin, 2002; DeLoache,
1991), finalizando el tercer año de vida, los niños de NSE medio comprendieron y usaron simbólicamente dibujos figurativos. El desempeño de los niños de NSE bajo, a la hora de interpretar la relación entre los dibujos y sus referentes tridimensionales, replica la trayectoria evolutiva reportada en Salsa (2012), donde niños de este grupo socioeconómico demostraron usar dibujos como símbolos recién a los 42 meses. Cabe destacar que en ambos estudios se empleó una tarea que controla los efectos de las etiquetas verbales utilizando objetos diferentes, pero sin un nombre distintivo, ya que los niños podrían basarse en el nombre del objeto representado como apoyo para establecer la relación entre la imagen y su referente (Callaghan, 2000). En futuras investigaciones, todavía resta indagar si las etiquetas verbales podrían tener un efecto facilitador en la emergencia de la comprensión de representaciones figurativas por parte de niños de NSE bajo.

En relación con la experiencia simbólica, las madres de los dos grupos socioeconómicos describieron una presencia variada de representaciones basadas en la imagen en sus hogares, aunque en el NSE medio los estímulos gráficos diseñados especialmente para niños tenían un predominio mayor. En contraposición con la investigación transcultural realizada por Callaghan et al. (2011), las diferencias en la comprensión simbólica no estarían en relación con una ausencia de imágenes en los hogares de los niños cuyo desempeño fue presimbólico, sino con una presencia baja de imágenes infantiles. Este tipo de representaciones, especialmente en libros, es utilizada en las familias occidentales de NSE medio como un recurso para el aprendizaje de palabras, de las convenciones de la lectoescritura y para la transmisión de conocimientos específicos, como por ejemplo conocimientos biológicos y numéricos (Anderson, Anderson \& Shapiro, 2005; Fletcher \& Reese, 2005; Ganea, Ma \& DeLoache, 2011). Esto podría ser parcialmente atribuible a las creencias de los padres acerca de que los libros y la lectura conjunta desempeñan un 
rol positivo en el desarrollo de los niños pequeños (Rideout, Vandewater \& Wartella, 2003).

En este sentido, en esta investigación se encontró que la frecuencia en el hogar de actividades compartidas por adultos y niños con imágenes, particularmente con imágenes audiovisuales y la lectura de cuentos, difería por nivel socioeconómico. Sería posible pensar entonces que las experiencias tempranas con imágenes que los niños tienen en sus entornos cotidianos les permitirían aprender las convenciones culturales y la función simbólica de esas representaciones. Si estas experiencias son escasas, o no están mediadas por usuarios expertos, la comprensión y el uso adecuado de las imágenes parecería emerger más tardíamente.

Las explicaciones acerca del porqué de estas diferencias exceden los límites de este trabajo, cuyo propósito fundamental consiste en la descripción de las experiencias con imágenes en el entorno familiar y su posible relación con la comprensión de dibujos. De todas formas, cabe señalar que probablemente el estilo de interacción desplegado por los adultos en estas experiencias tendría también un papel importante en las oportunidades de experiencia simbólica. Distintas investigaciones señalan que, en diferentes actividades conjuntas, el estilo de interacción de las madres de NSE medio parece ser más elaborado y demandante que el desplegado por sus pares de NSE bajo (Hoff-Ginsberg, 1991; Levin \& Aram, 2005; Ninio, 1980; Peralta \& Salsa, 2001).

Los resultados de la investigación, al mostrar variaciones de la experiencia con símbolos en dos niveles socioeconómicos, se alejan de una concepción de la experiencia simbólica solamente en términos del impacto acumulativo de la exposición a distintas clases de representaciones externas (DeLoache, 2002). Distintos autores que parten de una perspectiva sociocultural (Callaghan, 2013; Martí, 2003, 2012; Tomasello, 1999) concuerdan con que las formas de aprendizaje cultural serían cruciales ya que las imágenes, en tanto artefactos creados por el hombre, adquieren su significado en una matriz social: la construcción de significados y la formación del símbolo por parte del niño necesariamente requieren del intercambio social.

De esta manera, aún quedan cuestiones importantes pendientes de un análisis más exhaustivo. En primer lugar, de la misma manera que en investigaciones previas (Troseth et al., 2007), una limitación de este estudio es describir las experiencias infantiles con imágenes a partir de la información brindada por las madres. El diseño de investigaciones que empleen una metodología observacional naturalística es una cuestión pendiente en este campo. Este tipo de enfoque ayudaría a comprender qué sucede realmente en las interacciones de cada familia, conocer los materiales que eligen madres y padres para interactuar con sus hijos y la organización y estructuración de las actividades que diseñan. En esta línea, los métodos microgenéticos de análisis permitirían conocer cómo los adultos introducen gradualmente a los niños en el mundo de las imágenes: las acciones comunicativo-educativas de los adultos son esenciales para que los niños aprendan los usos simbólicos de las representaciones figurativas (Rodríguez \& Moro, 2002).

En segundo lugar, conocer mejor de qué modo los niños pequeños se apropian de estas representaciones en actividades cotidianas posibilitaría superar los tradicionales enfoques de déficit. Los enfoques de déficit se limitan a estimar el desempeño infantil en un dominio de conocimiento dado en términos de su adecuación o distancia respecto de parámetros unívocos, considerando para ello la edad o la condición social. La presente investigación, no obstante, intenta aportar evidencias acerca de que el aprendizaje de las formas de funcionamiento de las herramientas semióticas emerge al usarlas con otros en variados contextos de actividad; estos contextos podrían diferir en el menor o mayor acceso a los recursos semióticos o en los patrones de interacción en torno a ellos, no estando en correspondencia directa con el nivel socioeconómico como mostrarían las experiencias 
de las dos niñas de NSE bajo con desempeño simbólico en este estudio.

Finalmente, el conocimiento de estos contextos de actividad y de las trayectorias de aprendizaje de los niños podría contribuir, en el ámbito escolar, al diseño y la promoción de propuestas pedagógicas capaces de potenciar desde los primeros pasos unas formas de alfabetización gráfica más inclusivas y acordes a los desafíos sociales y comunicativos actuales.

\section{Referencias}

Anders, Y., Rossbach, H. G., Weinert, S., Ebert, S., Kuger, S., Lehl, S., \& Von Maurice, J. (2012). Home and preschool learning environments and their relations to the development of early numeracy skills. Early Childhood Research Quarterly, 27, 231-244. doi:10.1016/j. ecresq.2011.08.003

Anderson, A., Anderson, J., \& Shapiro, J. (2005). Supporting multiple literacies: Parents' and children's mathematical talk within storybook reading. Mathematics Education Research Journal, 16, 5-26. doi:10.1007/BF03217399

Braswell, G. S. (2001). Collaborative drawing during early mother-child interactions. Visual Arts Research, 27, 27-39.

Braswell, G. S., \& Callanan, M. A. (2003). Learning to draw recognizable graphic representations during mother-child interactions. Merrill-Palmer Quarterly, 49, 471-494. doi:10.1353/ mpq.2003.0019

Callaghan, T. C. (1999). Early understanding and production of graphic symbols. Child Development, 70, 1314-1324. doi:10.1111/1467-8624.00096

Callaghan, T. C. (2000). Factors affecting children's graphic symbol use in the third year: Language, similarity, and iconicity. Cognitive Development, 15, 185-214. doi:10.1016/S08852014(00)00026-5

Callaghan, T. C. (2013). Symbols and symbolic thought. En P. Zelazo (Ed.), The Oxford handbook of developmental psychology (pp. 974-1005). New York, NY: Oxford University Press.

Callaghan, T. C., Moll, H., Rakoczy, H., Warneken, F., Liszkowski, U., Behne, T., \& Tomasello, M. (2011). Early social cognition in three cultural contexts. Monographs of the Society for Research in Child Development, 76 (2, Serie N. ${ }^{\circ} 299$ ).

Callaghan, T. C., \& Rankin, M. P. (2002). Emergence of graphic symbol functioning and the question of domain specificity: A longitudinal training study. Child Development, 73, 359-376. doi:10.1111/1467-8624.00412

DeLoache, J. S. (1987). Rapid change in the symbolic functioning of very young children. Science, 238, 1556-1557. doi:10.1126/science. 2446392

DeLoache, J. S. (1991). Symbolic functioning in very young children: Understanding pictures and models. Child Development, 62, 737-752. doi:10.1111/j.1467-8624.1991.tb01566.x

DeLoache, J. S. (1995). Early understanding and use of symbols: The model model. Current Directions in Psychological Science, 4, 109-113. doi:10.1111/1467-8721.ep10772408

DeLoache, J. S. (2002). Early development of the understanding and use of symbolic artifacts. En U. Goswami (Ed.), Blackwell handbook of childhood cognitive development (pp. 206-226). Oxford, UK: Blackwell.

DeLoache, J. S., \& Burns, N. M. (1994). Early understanding of the representational function of pictures. Cognition, 52, 83-110. doi:10.1016/00100277(94)90063-9

DeLoache, J. S., Pierroutsakos, S. L, Uttal, D. H., Rosengren, K. S., \& Gottlieb, A. (1998). Grasping the nature of pictures. Psychological Science, 9, 205-210. doi:10.1111/1467-9280.00039

Fletcher, K. L., \& Reese, E. (2005). Picture book reading with young children: A conceptual framework. Developmental Review, 25, 64-103. doi:10.1016/j.dr.2004.08.009

Ganea, P.A., Ma, L., \& DeLoache, J. S. (2011). Young children's learning and transfer of biological 
information from picture books to real animals. Child Development, 82, 1421-1433. doi:10.1111/j.1467-8624.2011.01612.x

Goldin, G. (1998). Representational systems, learning, and problem solving in mathematics. Journal of Mathematical Behaviour, 17, 137-165. doi:10.1016/S0364-0213(99)80056-1

Gunderson, E., \& Levine, S. (2011). Some types of parent number talk count more than others: relations between parents' input and children's cardinal-number knowledge. Developmental Science, 14, 1021-1032. doi:10.1111/j.14677687.2011.01050.x

Harris, P. L., Kavanaugh, R. D., \& Dowson, L. (1997). The depiction of imaginary transformations: Early comprehension of a symbolic function. Cognitive Development, 12, 1-19. doi:10.1016/ S0885-2014(97)90028-9

Hoff, E. (2003). The specificity of environmental influence: Socioeconomic status affects early vocabulary development via maternal speech. Child Development, 74, 1368-1378. doi: 10.1111/1467-8624.00612

Hoff, E., Laursen, B., \& Tardif, T. (2002). Socioeconomic status and parenting. En M. H. Bornstein (Ed), Handbook of parenting: Biology and ecology of parenting, 2, (pp. 231-252). Mahwah, NJ: Lawrence Erlbaum.

Hoff-Ginsberg, E. (1991). Mother-child conversations in different social classes a nd communicative settings. Child Development, 62, 782-796. doi:10.1111/j.1467-8624.1991.tb011569.x

Levin, I., \& Aram, D. (2005). Children's names contribute to early literacy: A linguistic and a social perspective. En D. Ravid Diskin, \& H. Bat-Zeev Shyldkrot (Eds.), Perspectives on language and language development (pp. 219-241). Dordrecht: Kluwer Academic.

Liben, L. S. (1999). Developing an understanding of external spatial representations. En I. E. Sigel (Ed.), Development of mental representation. Theories and applications (pp. 297-321). Mahwah, NJ: Erlbaum.
Liben, L. S. (2008). Developing children's appreciation of photographs as informative and aesthetic artifacts. En C. Milbrath, \& H. M. Trautner (Eds.), Children's understanding and production of pictures, drawings, and art (pp. 155-184). Cambridge, MA: Hogrefe.

Martí, E. (2003). Representar el mundo externamente. La adquisición infantil de los sistemas externos de representación. Madrid: Machado Libros.

Martí, E. (2012). Desarrollo del pensamiento e instrumentos culturales. En M. Carretero \& J. A. Castorina (Comps.), Desarrollo cognitivo y educación [II]. Procesos del conocimiento y contenidos especificos (pp. 26-46). Buenos Aires: Paidós.

Ninio, A. (1980). Picturebook reading in mother-infant dyads belonging to two subgroups in Israel. Child Development, 62, 587-590. doi:10.2307/1129299

Peirce, C. S. (1932). Collected papers. Cambridge, MA: Harvard University Press.

Peralta, O. A., \& Salsa, A. M. (2001). Interacción materno-infantil con libros con imágenes en dos niveles socioeconómicos. Infancia y Aprendizaje, 24,325-339. doi:10.1174/021037001316949257

Pierroutsakos, S. L., \& DeLoache, J. S. (2003). Infants' manual exploration of pictorial objects varying in realism. Infancy, 4, 141-156. doi:10.1207/S15327078IN0401_7

Rideout, V. J., Vandewater, E. A., \& Wartella, E. A. (2003). Zero to six: Electronic media in the lives of infants, toddlers, and preschooler. Recuperado de http://kff.org/other/report/zeroto-six-electronic-media-in-the/

Rodríguez, C., \& Moro, C. (2002). Objeto, comunicación y símbolo. Una mirada a los primeros usos simbólicos de los objetos. Estudios de Psicología, 23, 323-338.

Salsa, A. M. (2012). Factores que influyen en la comprensión temprana de imágenes: $\mathrm{Si}$ militud perceptual y nivel socioeconómico. Infancia y Aprendizaje, 35, 313-326. doi:10.1174/021037012802238957 
Tomasello, M. (1999). The cultural origins of human cognition. Cambridge, MA: Harvard University Press.

Tomasello, M. (2014). A natural history of human thinking. Cambridge, MA: Harvard University Press.

Treiman, R., Schmidt, J., Decker, K., Robins, S., Levine, S., \& Demir, Ö. (2015). Parents' talk about letters with their young children. Child Development, 86, 1406-1418. doi:10.1111/ cdev. 12385

Troseth, G. L., Casey, A. M., Lawver, K. A., Walker, J. M., \& Cole, D. A. (2007). Naturalistic experience and the early use of symbolic artifacts.
Journal of Cognition and Development, 8, 309331. doi:10.1002/9781118963418.childpsy207 Vivaldi, R. A., \& Salsa, A. M. (2014). Artist's referential intention in early understanding of drawings as symbols. Estudios de Psicología, 35, 298-318. doi:10.1080/02109395.2014.922265

Vygotsky, L. S. (1978). Mind in society: The development of higher psychological processes. Cambridge, M.A.: Harvard University Press. Yamagata, K. (1997). Representational activity during mother-child interaction: The scribbling stage of drawing. British Journal of Developmental Psychology, 15, 355-366. doi:10.1111/j.2044835X.1997.tb00526.x

\section{Recibido: enero 15, 2016}

Aprobado: abril 26, 2017 
